\title{
The Librarian's Guide to Homelessness: An Empathy-driven Approach to Solving Problems, Preventing Conflict, and Serving Everyone
}

\section{Kaia MacLeod}

${ }^{1}$ School of Library and Information Studies, University of Alberta, kwmacleo@ualberta.ca:

\section{To Cite:}

MacLeod, K. (2020). The librarian's guide to homelessness: An empathy-driven approach to solving problems, preventing conflict, and serving everyone [Review of the book The librarian's guide to homelessness: An empathy-driven approach to solving problems, preventing conflict, and serving everyone, by R. J. Dowd]. Pathfinder: A Canadian Journal for Information Science Students and Early Career Professionals, 1(2), 65-67. https://doi.org/10.29173/pathfinder2

\section{Book Information}

Ryan J. Dowd, The librarian's guide to homelessness: an empathy-driven approach to solving problems, preventing conflict, and serving everyone, ALA Editions, 2018, ISBN: 978-0-8389-1626-1, 248 pp, \$75.05 CDN

common challenge for early-career librarians is learning to deal effectively with
all potential patrons, and an excellent place to start is Ryan Dowd's The Librarian's Guide to Homelessness: An Empathy-Driven approach to solving problems, preventing conflict, and serving everyone. The book works as a primer for new library staff, as well as a refresher on strategies to work with patrons currently experiencing homelessness. Beginning with common myths regarding homelessness, the author quickly moves into different strategies staff can take to better serve all of their library's patrons. 
The director of a large homeless shelter in the Chicago area, Dowd uses his legal background and Master's in Public Administration to inform his book. Although not a librarian himself, Dowd establishes his credibility with two decades of experience working with the homeless and his local shelter in Illinois; he has volunteered there since he was 13-years-old, and since served as the executive director after finishing law school.

The majority of the book discusses empathy-driven tools for staff and the best situations in which to use them. For instance, Dowd explains "The Cup Full of Pennies" concept, wherein every time you do something positive for the patron you add a mental penny to your cup. This can be as simple as introducing yourself or asking how you can help them. Whenever you roll your eyes, raise your voice, or use a punishment, you lose five pennies. In short, you want to keep a positive number of pennies. The 5:1 ratio balances the single negative interaction with five positive ones. The book is written in a conversational rather than academic tone with personal stories throughout, giving the book an accessible style. Dowd also uses popular culture in his writing, aligning the empathy tools with Jedi mind tricks and something that Batman would have in his tool belt.

Dowd uses catchy and engaging titles for the tools he describes as a way to keep his reader engaged. With names like "The Jerry Seinfeld," "The Echo," and "The 22 Pound Chocolate Smile," the book is an engaging read. It further divides the tools into three categories: mind, body, and words. It also explains interesting points, like how people experiencing homelessness pay more attention to physical cues. So, although one may be speaking politely, a clenched fist is not putting anyone at ease. At the same time, the tools cover a wide array of situations. A majority of the situations and tools that the author describes can be relevant for patrons in general. Another highlight of the book is Dowd's personal stories. Because he has significant experience, he draws on his past. Those who have worked with the public may find sentiments reflected here.

Although beneficial for a number of organizations, this book would be a great addition to any library, especially those with patrons and staff who are interested in a social work career path. For smaller libraries, it would be a good idea to ensure that the 
book is available through interlibrary loan or a library consortium because it should be made available wherever staff interacts with the public.

\section{Conflict of Interest Statement}

None declared. 